\title{
Common menstrual disorders in adolescent girls attending a tertiary care center
}

\author{
Hibina K. P. ${ }^{1}$, Nishi Roshini K. ${ }^{1 *}$, Andrews M. A. ${ }^{2}$
} ${ }^{1}$ Department of Obstetrics and Gynecology, ${ }^{2}$ Department of Medicine, Government Medical College, Thrissur, Kerala,
India

Received: 01 January 2020

Accepted: 06 February 2020

*Correspondence:

Dr. Nishi Roshini K.,

E-mail: nishiroshini@gmail.com

Copyright: () the author(s), publisher and licensee Medip Academy. This is an open-access article distributed under the terms of the Creative Commons Attribution Non-Commercial License, which permits unrestricted non-commercial use, distribution, and reproduction in any medium, provided the original work is properly cited.

\begin{abstract}
Background: Menstrual disorders are an important cause of concern among adolescent girls. Most problems are physiological but few have underlying pathology which has adverse effect on the future reproductive health Aim of the study was to know the prevalence and to evaluate the underlying cause of the menstrual problems in adolescent girls seeking medical care.

Methods: This is a cross sectional study conducted in in 215 adolescent girls aged 13-19 years who sought medical care over a period of 12 months for menstrual complaints from the department of obstetrics and gynecology, Govt. Medical College, Thrissur, a tertiary care center in middle of Kerala, South India. Data was analyzed by SPSS software and $\mathrm{p}$ value $<0.05$ was taken statistically significant.

Results: Dysmenorrhea was the most common problem (57.5\%), followed by scanty menstruation (35.35\%) and $25.2 \%$ of girls suffered from premenstrual symptoms. Hypothyroidism was seen in $2.4 \%$ of girls $40 \%$ were anemic. Statistically significant association was found between hypothyroidism and features of hyperandrogenemia with cycle irregularity. Ultrasonographic evidence of polycystic ovarian morphology was identified among $61.9 \%$ girls with irregular cycles.

Conclusions: Even though majority of menstrual issues are self-limiting proper evaluation and follow up for medical disorders like hypothyroidism and anemia are important and appropriate intervention is crucial for future reproductive and general health of adolescents presenting with Menstrual disorders.
\end{abstract}

Keywords: Adolescents, Dysmenorrhea, Hyperandrogenism, Hypothyroidism

\section{INTRODUCTION}

The word adolescent derived from of the Latin word, adolescent remaining "growing to maturity" WHO defines this phase from 10 years of age to 19 years. ${ }^{1}$ Onset of menarche is an important milestone in puberty. Girls suffers various problems during this period. The main problems are psychological adjustment with menstruation, premenstrual symptoms and disorders of menstrual blood flow. Many a times the menstrual irregularities are attributed to incomplete maturation of
Hypothalamic-pituitary-ovarian axis. It may be due to underlying organic causes like polycystic ovarian syndrome, endometriosis or hypogonadism. ${ }^{2}$ In today's world the life style issues like consumption of junk foods and lack of physical activity and exposure to excess stress in school and home are considered as important factors responsible for menstrual disturbances in the adolescent girls. ${ }^{3}$

Treatment seeking behaviour may be adversely influenced by rigid traditional norms and practices, 
ignorance, myths and taboos, lack of adolescent friendly health care facilities etc. Understanding the common menstrual problems and barriers to the treatment seeking behaviour of the adolescent girls will help us in planning effective healthcare implementation programs for this vulnerable group.

The present study aims to assess the prevalence of common menstrual problems in adolescent girls attending outpatient and inpatient clinic in the department of obstetrics and gynecology at Govt. Medical college, Thrissur and to identify the factors associated with these problems.

\section{METHODS}

This is a cross sectional study conducted in the department of obstetrics and gynecology over a period of 12 months (October 2016 to October2017) to analyze the prevalence of common menstrual disorders in adolescent girls aged 13-19 years and to evaluate common causes for them.

Written consent was obtained from the parent or guardian. 215 girls were surveyed by structured questionnaire, which included demographic details, menstrual details, menstrual problems (dysmenorrhea, irregular cycles, scanty/heavy flow, premenstrual symptoms), preexisting medical disorders and relevant family history, lifestyle factors like consumption of junk food, missing of academic activities due to these problems were analyzed. Participants were subjected to relevant investigations. Ultrasound evaluation was done for all. Treatment seeking behavior was also assessed.

\section{Statistical analysis}

The data obtained were analyzed using SPSS software. The statistical significance was ascertained by $\mathrm{p}$ value $<0.05$.

\section{RESULTS}

The mean age of menarche was 11.16 years and the mean age of presentation 16.45 years. The menstrual characteristics is given in Table 1 .
Table 1: Menstrual characteristics of adolescent girls with menstrual disorders in Thrissur, India.

\begin{tabular}{|ll|}
\hline Variables & $\mathbf{N}(\%)$ \\
\hline Menarche & $8(3.74)$ \\
\hline Early <10 years & $6(2.84)$ \\
\hline Delayed $>15$ years & 11.16 years \\
\hline Mean age & \\
\hline Cycle length & $9(4.2)$ \\
\hline$<21$ days & $141(65.4)$ \\
\hline $21-35$ days & $65(30.4)$ \\
\hline$>35$ days & \\
\hline Duration of flow & $26(12.1)$ \\
\hline$<4$ days & $143(66.8)$ \\
\hline $4-7$ days & $46(21.0)$ \\
\hline$>7$ days & \\
\hline No of pads/day & $50(23.4)$ \\
\hline$<3$ & $147(68.2)$ \\
\hline $3-5$ & $18(8.4)$ \\
\hline$>5$ & $65(30.4)$ \\
\hline Oligomenorrhoea & $9(4.2)$ \\
\hline Polymenorrhoea & $64(29.7)$ \\
\hline Heavy cycles & $76(35.3)$ \\
\hline Scanty cycles & $54(25.2)$ \\
\hline Premenstrual syndrome & $106(49.5)$ \\
\hline School absenteeism & \\
\hline
\end{tabular}

Table 2: Premenstrual symptoms in adolescent girls with menstrual disorders in Thrissur, India.

\begin{tabular}{|lll|}
\hline Premenstrual symptom & Number & Percentage \\
\hline Headache & 32 & 59.2 \\
\hline Bloating sensation & 9 & 16 \\
\hline Breast soreness & 16 & 29.6 \\
\hline Sleep disturbance & 2 & 3.7 \\
\hline Mood variation & 20 & 37 \\
\hline Anxiety/ irritability & 4 & 7.4 \\
\hline
\end{tabular}

Most common premenstrual symptom was headache in $32(59.2 \%)$ followed by mood variations 20 (37\%) Various premenstrual symptoms and their proportion is given in Table 2. Correlation between body mass index (BMI) and cycle regularity is given in Table 3.

Table 3: Relation between BMI and cycle regularity in adolescent girls with menstrual disorders in Thrissur, India.

\begin{tabular}{|c|c|c|c|c|c|c|}
\hline \multirow{2}{*}{ BMI $\left(\mathrm{kg} / \mathrm{m}^{2}\right)$} & \multicolumn{4}{|c|}{ Regularity } & \multirow[t]{2}{*}{ Total } & p value \\
\hline & Number & Regular \% & Irregular number & $\%$ & & \multirow{5}{*}{ p 0.208} \\
\hline $18.5-23.49$ & 20 & $9.30 \%$ & 24 & 11.16 & 44 & \\
\hline $23.5-29.9$ & 72 & $33.49 \%$ & 47 & 21.86 & 119 & \\
\hline$>30$ & 27 & $12.56 \%$ & 25 & 11.63 & 52 & \\
\hline Total & 119 & $55.35 \%$ & 96 & 44.65 & 215 & \\
\hline
\end{tabular}


No statistically significant association was noted between BMI and cycle irregularity (p 0.208).

Hypothyroidism was present in $2.4 \%(5 / 215)$ of adolescents presented with menstrual disorders. Other medical disorders are shown in Table 4. Statistically significant association was noted between hypothyroidism and cycle irregularity (p 0.002) Table 5.
Table 4: Medical disorders in adolescent girls with menstrual disorders in Thrissur, India.

\begin{tabular}{|lll|}
\hline Disease & Number & Percentage \\
\hline Hypothyroidism & 5 & 2.4 \\
\hline ITP & 2 & 0.9 \\
\hline Renal disease & 2 & 0.9 \\
\hline Total & 9 & 4.2 \\
\hline
\end{tabular}

Table 5: Relation between thyroid function test (TFT) and cycle regularity in adolescent girls with menstrual disorders in Thrissur, India.

\begin{tabular}{|c|c|c|c|c|c|c|}
\hline \multirow{2}{*}{ TFT } & \multicolumn{4}{|c|}{ Regularity } & \multirow[b]{2}{*}{ Total } & \multirow[b]{2}{*}{ p value } \\
\hline & Regular & $\%$ & Irregular & $\%$ & & \\
\hline Normal & 113 & 59.8 & 76 & 40.2 & 189 & \multirow{3}{*}{0.002} \\
\hline Hypothyroid & 7 & 27 & 19 & 73 & 26 & \\
\hline Total & 120 & & 95 & & 215 & \\
\hline
\end{tabular}

Table 6: Medical disorders and flow duration in adolescent girls with menstrual disorders in Thrissur, India.

\begin{tabular}{|c|c|c|c|c|c|c|}
\hline \multirow{2}{*}{ Duration of flow } & \multicolumn{2}{|c|}{ Hypothyroidism } & \multicolumn{2}{|l|}{ ITP* } & \multicolumn{2}{|c|}{ Renal disease } \\
\hline & Number & $\%$ & Number & $\%$ & Number & $\%$ \\
\hline$<4$ days & 0 & 0 & 0 & 0 & 0 & 0 \\
\hline 4-7 days & 2 & 40 & 1 & 50 & 1 & 50 \\
\hline$>7$ days & 3 & 60 & 1 & 50 & 1 & 50 \\
\hline Total & 5 & 100 & 2 & 100 & 2 & 100 \\
\hline
\end{tabular}

Table 7: Relation between medical disorders and cycle length in adolescent girls with menstrual disorders in Thrissur, India.

\begin{tabular}{|c|c|c|c|c|c|c|}
\hline & \multicolumn{2}{|c|}{ Hypothyroidism } & \multicolumn{2}{|l|}{ ITP } & \multicolumn{2}{|c|}{ Renal disease } \\
\hline Cycle length & Number & $\%$ & Number & $\%$ & Number & $\%$ \\
\hline$<21$ days & 1 & 20 & 0 & 0 & 0 & 0 \\
\hline 21-35 days & 1 & 20 & 2 & 100 & 1 & 50 \\
\hline$>35$ days & 3 & 60 & 0 & 0 & 1 & 50 \\
\hline Total & 5 & 100 & 2 & 100 & 2 & 100 \\
\hline
\end{tabular}

Table 8: Prevalence of hyperandrogenic features in adolescent girls with menstrual disorders in

Thrissur, India.

\begin{tabular}{|lll|}
\hline Features & Number & Percentage \\
\hline Acne & 19 & 8.9 \\
\hline Hirsutism & 11 & 5.1 \\
\hline Acanthosis Nigricans & 28 & 13.1 \\
\hline Total & 58 & 26.9 \\
\hline
\end{tabular}

Table 9: Relation between hyperandrogenic features and cycle regularity in adolescent girls with menstrual disorders in Thrissur, India.

\begin{tabular}{|llllll|}
\hline Hyperandrogenic features & \multicolumn{2}{l}{ Cycle regularity } & \multicolumn{2}{c|}{ p value } \\
\hline Acne & Regular & $\mathbf{\%}$ & Irregular & $\mathbf{\%}$ & \\
\hline Hirsutism & 2 & 10.5 & 17 & 89.4 & 0.00 \\
\hline Acanthosis Nigricans & 2 & 18.2 & 9 & 81.8 & 0.01 \\
\hline
\end{tabular}

Among 2 girls with ITP, both had regular cycles and one had heavy cycles. Among, 2 girls with renal disease, one had infrequent heavy cycles. Infrequent heavy cycles were seen in $60 \%$ of hypothyroid girls (Table 6 and 7).

Features of hyperandrogenism was noted in 58 girls (26.9\%). Acanthosis nigricans was the commonest feature noted $(13.1 \%)$ Table 8. 
Girls with hyperandrogenic features had predominantly irregular cycles and the relation was statistically significant (Table 9).

Features of polycystic ovaries were seen in $21(9.8 \%)$ and simple ovarian cyst in $7(3.3 \%)$ and normal ultra sound study in 184 (85.5) Table 10 and among 2 girls with endometrioma, one had frequent cycles. Relation with pelvic pathology and menstrual disorders are shown in Table 11.
Table 10: USG findings in adolescent girls with menstrual disorders in Thrissur, India.

\begin{tabular}{|lll|}
\hline USG finding & Number & Percentage \\
\hline Normal & 184 & 85.5 \\
\hline Polycystic ovaries & 21 & 9.8 \\
\hline Simple Ovarian cyst & 7 & 3.3 \\
\hline Haemorrhagic cyst & 1 & 0.5 \\
\hline Endometrioma & 2 & 0.9 \\
\hline Total & 215 & 100.0 \\
\hline
\end{tabular}

Table 11: Relation between pelvic pathology and cycle problems in adolescent girls with menstrual disorders in Thrissur, India.

\begin{tabular}{|lllll|}
\hline Pathology & Irregular cycles & $\%$ & Dysmenorrhea & $\%$ \\
\hline PCOS & 13 & 61.9 & 10 & 47.6 \\
\hline Haemorrhagic cyst & 0 & 0 & 1 & 100 \\
\hline Endometrioma & 1 & 50 & 1 & 50 \\
\hline Simple ovarian cyst & 6 & 85.7 & 4 & 57 \\
\hline
\end{tabular}

Table 12: Prevalence of junk food intake and cycle regularity in adolescent girls with menstrual disorders in Thrissur, India.

\begin{tabular}{|c|c|c|c|c|c|c|}
\hline \multirow{2}{*}{ Junk food intake } & \multicolumn{4}{|c|}{ Regularity } & \multirow{2}{*}{ Total } & \multirow{2}{*}{ p value } \\
\hline & Regular & $\%$ & Irregular & $\%$ & & \\
\hline Weekly & 2 & 20 & 8 & 80 & 10 & \multirow{4}{*}{0.06} \\
\hline Monthly & 11 & 55 & 9 & 45 & 20 & \\
\hline Occasional & 107 & 57.8 & 78 & 42.2 & 185 & \\
\hline Total & 120 & & 95 & & 215 & \\
\hline
\end{tabular}

Table 13: Mode of treatment received by adolescent girls with menstrual disorders in Thrissur, India.

\begin{tabular}{|lll|}
\hline Mode of treatment & Number & Percentage \\
\hline Analgesics & 96 & 44.3 \\
\hline Oral iron & 4 & 1.8 \\
\hline Blood transfusion & 1 & 0.4 \\
\hline Hormonal agents & 25 & 11.2 \\
\hline Total & 126 & 58.6 \\
\hline
\end{tabular}

All girls included in the study report consumption of junk food items at least occasionally. Among 10 girls who consume it on weekly basis, $8(80 \%)$ had irregular cycles. (p 0.06) which is close to significant level

Mode of medical treatment underwent is given in Table 13. Blood transfusion was needed for one girl and 96 (44.3\%) used analgesics.

\section{DISCUSSION}

The mean age of menarche was 11.16 years and the mean age of presentation 16.45 years. The commonest presenting problem was dysmenorrhea (57.3\%). The estimated prevalence of dysmenorrhea varies from $20 \%$ to $95 \%$ in various studies. ${ }^{4}$ Irregular cycles reported in this study is $44.65 \%$ which is much higher when compared to other Indian studies. Sheetu et al, reported $24.3 \%$ of adolescent girls suffer from irregular cycles. ${ }^{5}$ Nirmala et al reported that $29 \%$ of girls had irregular cycles in their studies. ${ }^{6}$ In our study infrequent cycles (> 35 days) were found to be common (30.4\%) than frequent cycles $(<21$ days) $(4.2 \%)$.

Study did not show any statistically significant association between BMI and cycle regularity though $(46.05 \%)$ were overweight and obese. Study by Nabila et al had shown statistically significant association between the two. ${ }^{7}$

In this study $29.7 \%$ of girls suffered from heavy flow during their cycle. Study by Das et al, showed heavy flow in up to $33.3 \%$, caused by PCOS and hypothyroidism. ${ }^{8}$ Hypothyroidism was the commonest medical disorder noted in the study $(2.4 \%)$. Infrequent heavy cycles were seen in $60 \%$ of hypothyroid girls. Statistically significant association was noted between hypothyroidism and cycle irregularity. Joshy et al, has described cycle irregularity in $78 \%$ hypothyroid women, predominantly characterized by infrequent and heavy cycles which is similar to the present study. ${ }^{9}$ In this study $25.2 \%$ of girls complained of symptoms of premenstrual syndrome. Sheetu et al, has described $51.5 \%$ of girls suffered from premenstrual 
syndrome. ${ }^{5}$ The commonest symptom noted in our study was headache followed by mood disturbance.

In this study 21 girls showed ultrasound evidence of polycystic ovaries $(9.8 \%)$ and out of them $61.9 \%$ had irregular periods and $26.9 \%$ had hyper and organic features. Statistically significant association was noted between hyperandrogenic features and cycle irregularity. Mumbai based study done by Beena et al, also showed similar prevalence of PCOS $(22.8 \%)$ and the prevalence of irregular cycles up to $92 \% .{ }^{10}$ Irregular cycles were seen in $85.7 \%$ girls with simple cyst.

Consumption of junk food items on a weekly basis was seen in $4.6 \%$ and $80 \%$ of them had irregular cycles (p $0.06)$ which is close to significant level. ${ }^{9}$ Nirmala et al, has shown statistically significant association between consumption of junk food with irregular cycles dysmenorrhea and PMS (pre-menstrual syndrome).

Dysmenorrhea was the leading cause for missed school activities (49.5\%). Analgesics were taken by $44.3 \%$. Nirmala et al has also described similar incidence $(31 \%)$ in her study. ${ }^{6}$ School based study by Resmy et al, had shown that $17.6 \%$ of girls sought treatment for dysmenorrhea. ${ }^{11}$ In a study from Turkey analgesic use in the dysmenorrhea group was higher than in the control group $(69.9 \%$ versus $46.8 \%$, $\mathrm{p}<0.05) .{ }^{12}$ Anemia was seen in $40.19 \%$ but only $1.8 \%$ gave history of iron intake. One girl required blood transfusion for severe anemia and 25 girls $(11.2 \%)$ were treated with hormonal agents.

\section{CONCLUSION}

Dysmenorrhea was the most common problem (57.5\%) for which the adolescents sought medical care, which was followed by scanty menstruation $(35.35 \%)$ and heavy flow $(29.7 \%)$ pre-menstrual symptoms were reported in (25.2\%) girls. Dysmenorrhea was a leading cause for missed school activities (49.5\%). The most common medical disorder associated was hypothyroidism $(2.4 \%)$ and $40 \%$ girls were anemic and they were not on iron supplementation.

Adolescent girls should be taught to chart their menstrual cycle frequency and regularity and bleeding pattern so that it helps to identify the exact menstrual problems. Clinicians need to focus more on adolescent health and health education programmes. We recommend large studies to be conducted in schools and colleges to find the prevalence of menstrual disorders and their etiologies.

Funding: No funding sources Conflict of interest: None declared
Ethical approval: The study was approved by the Institutional Ethics Committee

\section{REFERENCES}

1. Waghachavare VB, Chavan VM, Dhumale GB. a study of menstrual problems among the female junior college students from rural. Natl J Commu Med. 2013;4(2):236-40.

2. Rebar R. Evaluation of amenorrhea, anovulation, and abnormal bleeding. Endo text. 2000. Available at: http://www.ncbi.nlm.nih.gov/pubmed/25905367.

Accessed 6 January 2020.

3. Datar A, Nicosia N. Junk food in schools and childhood obesity. J Policy Anal Manag. 2012;31(2):312-37.

4. Joshi T, Patil A, Kural M, Noor N, Pandit D. Menstrual characteristics and prevalence of dysmenorrhea in college going girls. J Fam Med Prim Care. 2015;4(3):426.

5. Jailkhani SM, Naik JD, Thakur MS, Langre SD, Pandey VO. Patterns \& problems of menstruation amongst the adolescent girls residing in the urban slum. Sch J App Med Sci. 2014;2(2A):529-34.

6. Lakkawar NJ, Jayavani RL, Nivedhana Arthi P, Alaganandam P, Vanajakshi N. A study of menstrual disorders in medical students and its correlation with biological variables. Sch J App Med Sci. 2014;2(6E):3165-75.

7. Ali Abdella DNH, Nasr Abd-Elhalim DEH, Fathy Attia DAM. The body mass index and menstrual problems among adolescent students. IOSR J Nurs Heal Sci. 2016;5(4):13-21.

8. Prasad DB, Jagannath P, Bora BMK. Evaluation of menorrhagia in adolescent girls: a clinical study. Sch J Appl Med Sci. 2016;4(6):2307-11.

9. Joshi JV, Bhandarkar SD, Chadha M, Balaiah D, Shah R. Menstrual irregularities and lactation failure may precede thyroid dysfunction or goitre. J Postgrad Med. 1993;39(3):137-41

10. Joshi B, Mukherjee S, Patil A, Purandare A, Chauhan S, Vaidya R. A cross-sectional study of polycystic ovarian syndrome among adolescent and young girls in Mumbai, India. Indian J Endocrinol Metab. 2014;18(3):317-24.

11. Raveendran R, Jacob A, Ismail J. A delve into the menstrual problems in teenagers: a cross sectional study in an urban school in Kerala, India. Int $\mathrm{J}$ Reprod Contracept Obstet Gynecol. 2016;5(11):3978-82.

12. Oksuz E, Sozen F, Kavas E, Arik EP, Akgun Y, Bingol $\mathrm{P}$, et al. Usage of analgesics among young girls and dysmenorrhea. Konuralp Tip Derg. 2017;9(3):37-45.

Cite this article as: Hibina KP, Nishi Roshini K, Andrews MA. Common menstrual disorders in adolescent girls attending a tertiary care center. Int J Reprod Contracept Obstet Gynecol 2020;9:1164-8. 